\title{
Accelerated Adoption of Advanced Health Information Technology in Beacon Community Health Centers
}

\author{
Emily Jones, PhD, MPP, and Michael Wittie, MPH
}

Background: To complement national and state-level HITECH Act programs, 17 Beacon communities were funded to fuel community-wide use of health information technology to improve quality. Health centers in Beacon communities received supplemental funding.

Methods: This article explores the association between participation in the Beacon program and the adoption of electronic health records. Using the 2010-2012 Uniform Data System, trends in health information technology adoption among health centers located within and outside of Beacon communities were explored using differences in mean $t$ tests and multivariate logistic regression.

Results: Electronic health record adoption was widespread and rapidly growing in all health centers, especially quality improvement functionalities: structured data capture, order and results management, and clinical decision support. Adoption lagged for functionalities supporting patient engagement, performance measurement, care coordination, and public health. The use of advanced functionalities such as care coordination grew faster in Beacon health centers, and Beacon health centers had 1.7 times higher odds of adopting health records with basic safety and quality functionalities in 2010-2012.

Discussion: Three factors likely underlie these findings: technical assistance, community-wide activation supporting health information exchange, and the layering of financial incentives. Additional technical assistance and community-wide activation is needed to support the use of functionalities that are currently lagging. (J Am Board Fam Med 2015;28:565-575.)

Keywords: Delivery of Health Care; Electronic Medical Records; Health Policy; Information Systems; Populations, Underserved

Health information technology (IT) enables quality improvement and is foundational to current delivery system transformation efforts. ${ }^{1-3}$ The 2009 Health Information Technology for Economic and Clinical Health (HITECH) $\mathrm{Act}^{4}$ supports providers and hospitals in adopting interoperable health IT and making the workflow changes to improve

This article was externally peer reviewed.

Submitted 21 January 2015; revised 14 April 2015; accepted 20 April 2015.

From the Division of Behavioral Health and Intellectual Disabilities Policy, Office of Disability, Aging, and LongTerm Care Policy, Office of the Assistant Secretary for Planning and Evaluation, US Department of Health and Human Services, Washington, DC (EJ); Department of Health Policy and Management, The Milken Institute School of Public Health and Health Services, The George Washington University, Washington, DC (EJ); the Office of Clinical Safety and Quality, Office of the National Coordinator for Health Information Technology, US Department of Health and Human Services, Washington, DC (MW).

Funding: none. and coordinate clinical care. ${ }^{5}$ The Medicare and Medicaid Electronic Health Record (EHR) incentive programs provide funding to eligible providers and hospitals for demonstrating "meaningful use" of certified EHRs that have specific safety- and quality-related functionalities. ${ }^{6,7}$ Programs also were created to train the health IT workforce, ${ }^{8}$ provide technical assistance with implementation and optimization, ${ }^{9,10}$ and support interoperable health information exchange. ${ }^{11}$ There is evidence

Conflict of interest: none declared.

Disclaimer: This article represents the views of the authors, not the Department of Health and Human Services.

Corresponding author: Emily Jones, $\mathrm{PhD}, \mathrm{MPP}$, Division of Behavioral Health and Intellectual Disabilities Policy, Office of Disability, Aging, and Long-Term Care Policy Office of the Assistant Secretary for Planning and Evaluation, US Department of Health and Human Services, Office \# 424E.24, 200 Independence Ave SW, Washington, DC 20201 (E-mail: Emily.Jones@hhs.gov). 
Table 1. Key Features of the Beacon Communities Program

\begin{tabular}{|c|c|}
\hline Program Feature & Description \\
\hline Funding & $\begin{array}{l}\text { Seventeen communities each received approximately } \$ 11-16 \text { million } \\
\text { each to build and strengthen the health information technology } \\
\text { infrastructure in each community, use health information } \\
\text { technology to drive quality improvement, and test innovative } \\
\text { practices. }\end{array}$ \\
\hline Community-level focus & $\begin{array}{l}\text { Of the } 17 \text { Beacon communities, } 1 \text { was urban, } 7 \text { were predominantly } \\
\text { rural, and } 7 \text { were a mix of both urban and rural localities. } \\
\text { Different communities defined themselves in various ways; some } \\
\text { Beacon communities attempted to change the entire delivery } \\
\text { system in their community, whereas others focused more } \\
\text { narrowly. }\end{array}$ \\
\hline Collaborative governance & $\begin{array}{l}\text { To ensure that each Beacon was responsive to the needs of the } \\
\text { community, Beacon grantees were required to engage multiple } \\
\text { stakeholders in decision-making regarding the goals and } \\
\text { interventions that were pursued. Partnerships within the } \\
\text { communities were forged and strengthened during the Beacon } \\
\text { program. }\end{array}$ \\
\hline Specific objectives & $\begin{array}{l}\text { Each community honed the objectives from their funding proposal } \\
\text { into specific, measurable goals that could be achieved during the } \\
2 \text {-year project period. }\end{array}$ \\
\hline Interventions tied to the objectives of each community & $\begin{array}{l}\text { Once each community winnowed their objectives down to specific, } \\
\text { measurable goals, they received technical assistance to design and } \\
\text { implement interventions to work toward those goals. }\end{array}$ \\
\hline Measuring and reporting performance & $\begin{array}{l}\text { Beacon communities were required to report, on a quarterly basis, } \\
\text { performance measures of their choosing. The measures were } \\
\text { selected to reflect improvements on the objectives of each } \\
\text { community. Technical assistance for extracting, aggregating, and } \\
\text { reporting the data was provided. }\end{array}$ \\
\hline Data feedback for quality improvement & $\begin{array}{l}\text { Each quarter, the Beacon communities received a feedback report } \\
\text { that was based on analysis of Medicare claims data. The feedback } \\
\text { report highlighted patterns in utilization and costs, and } \\
\text { communities received technical assistance with interpreting the } \\
\text { feedback reports and changing their approaches to pursuing their } \\
\text { objectives based on the feedback reports. }\end{array}$ \\
\hline
\end{tabular}

that the HITECH Act spurred rapid adoption of health IT in the United States. ${ }^{12,13}$

In addition to the programs implemented at the national and state levels, the Beacon Community Program was created to accelerate existing broad community partnerships and engagement in using health IT to transform health care. Seventeen Beacon communities located throughout the United States received a total of $\$ 250$ million in 2010 to build and strengthen health IT infrastructure, support the use of health IT to improve clinical care, and test innovative interventions. ${ }^{14}$ Each community set specific goals and chose interventions appropriate for their local context. ${ }^{15,16}$ In addition to funding, the Beacon communities received technical assistance with their delivery system transformation goals. See Table 1 for more details on the Beacon Communities Program.

Before the HITECH Act, there was evidence of a digital divide in health IT adoption; providers in resource-scarce and rural settings were less likely to have robust health IT infrastructure compared with their peers. ${ }^{17,18}$ To encourage federally qualified health centers (hereafter, "health centers") to participate in the Beacon Community Program initiatives, the Health Resources and Services Administration (HRSA) provided \$8.5 million in supplemental funding to the 85 health centers located in Beacon communities in September 2011. All eligible health centers received $\$ 100,000$ of supplemental funding and were required to participate in the Beacon efforts in their local areas. This investment built on existing foundations of support for health IT adoption among health centers, including $\$ 1.5$ billion in the HITECH Act for infrastructure investments in health centers, including purchasing and upgrading health IT. ${ }^{19}$ Spurred by core program requirements including quality reporting and improvement activities, health centers have long worked collaboratively to use health IT to support quality improvement. ${ }^{20-26}$ Recent data show that health centers are adopting EHRs apace with, or even 
more rapidly than, other ambulatory providers in the United States. ${ }^{27,28}$

This study is, to our knowledge, the first to examine the impact of the Beacon program on health centers. Understanding the interaction between community-based transformation efforts and federal- and state-level initiatives supporting health IT adoption is useful to inform future policy. We believe this is also the first study to present quantitative, national results of how the Beacon program may have affected the structure of the health care delivery system; prior studies focused only on particular communities. This study explored 3 research questions: (1) In 2010, 2011, and 2012, what was the level of adoption and use of EHRs in health centers in Beacon communities compared with non-Beacon health centers? (2) Controlling for other relevant factors, were Beacon health centers more likely than non-Beacon health centers to adopt EHRs with basic safety and quality features between 2010 and 2012? (3) At baseline and in 2012, did Beacon and non-Beacon health centers show different patterns in the adoption of specific health IT functionalities?

\section{Methods}

This study uses administrative data from the 2010, 2011, and 2012 Uniform Data System (UDS), which is maintained by the HRSA. HRSA staff and contractors perform extensive validation of the selfreported data from each health center. Each health center organization that receives federal funding under Section 330 of the Public Health Service Act is required to submit UDS data annually. UDS data are reported at the organization level; most organizations operate multiple care delivery sites. The analysis includes the universe of federally funded health centers, since they are all required to report to the UDS. In addition to the 85 health centers located in Beacon communities, we analyzed data from 1038 non-Beacon health centers in 2010, 1043 in 2011, and 1113 in 2012.

The UDS includes information about whether each health center had an EHR, whether it was in use by all medical providers at all sites, and details on the use of IT functionalities. Before 2010, UDS did not collect data on EHR adoption. Based on the previous literature, ${ }^{11}$ a variable was created to represent adoption of an EHR with basic safety and quality functionalities if the health center had an
EHR in use at all clinic sites and used the following 7 functionalities: capture of patient history and demographic information, clinical notes, problem list, medication list, electronic prescription entry, lab results incorporated into the EHR, and radiology results incorporated into the EHR. Since EHR products vary, using the "basic" definition facilitates comparisons based on safety- and qualityenhancing functionalities.

\section{Analysis}

We calculated pooled 2010 to 2012 descriptive statistics for health center and patient caseload characteristics, and we conducted $t$ tests of independent samples differences in means between Beacon and non-Beacon health centers. Multivariate logistic regression models explored the association between being in a Beacon community and adopting an EHR with basic safety and quality functionalities between 2010 and 2012, controlling for relevant health center characteristics and patient demographics. Sensitivity analysis was conducted using a difference in differences analysis. The dichotomous dependent variable indicated whether the health center had a basic EHR system in 2012, but not in 2010. Independent variables were included in the model because the literature indicates that they are factors that might be associated with ambulatory health IT infrastructure. ${ }^{29-31}$ The independent variables in the final models were urbanicity, region, size (the number of patients served annually), the percentage of each health center's caseload living below the federal poverty level, the percentage of patients who were Hispanic/Latino, the percentage of patients of non-Hispanic/Latino ethnicity reporting black/African American race, and the percentage of nonHispanic/Latino patients reporting other race. Since this study involved the secondary use of administrative data, institutional review board approval was not necessary. Analyses were conducted using Stata software version 12.0 (StataCorp, College Station, TX).

\section{Results}

The 85 health center organizations that were located in Beacon communities and received supplemental funding were larger than other health centers. Each Beacon health center served over 20,516 patients annually, on average, compared with 
Table 2. Health Center and Patient Characteristics, by Beacon Community Status, 2010-2012

\begin{tabular}{|c|c|c|c|}
\hline Characteristics & Overall & $\begin{array}{l}\text { Non-Beacon } \\
\text { Community }\end{array}$ & Beacon Community \\
\hline \multicolumn{4}{|l|}{ Health centers } \\
\hline Patients served annually at each health center (mean no.) & $17,646.60$ & $17,417.23$ & $20,516.00^{*}$ \\
\hline Rural & 47.52 & 47.96 & 41.96 \\
\hline \multicolumn{4}{|l|}{ Region } \\
\hline South & 34.51 & 35.49 & $22.35^{\dagger}$ \\
\hline Northeast & 17.65 & 17.46 & 20.00 \\
\hline Midwest & 18.90 & 18.53 & $23.53^{\ddagger}$ \\
\hline West & 28.94 & 28.53 & 34.12 \\
\hline \multicolumn{4}{|l|}{ Receive funding to target services to special populations } \\
\hline Homeless & 19.59 & 19.81 & 16.86 \\
\hline Migrant and seasonal farm workers & 13.99 & 13.89 & 15.29 \\
\hline $\begin{array}{l}\text { Accreditation or patient-centered medical home } \\
\text { recognition (mean \%) }\end{array}$ & 32.97 & 32.61 & 37.65 \\
\hline \multicolumn{4}{|l|}{ Patient demographics } \\
\hline$<100 \% \mathrm{FPL}$ & 68.58 & 68.59 & 68.47 \\
\hline \multicolumn{4}{|l|}{ Insurance status and type } \\
\hline Uninsured & 39.29 & 39.28 & 39.40 \\
\hline Medicaid & 34.00 & 33.83 & $36.14^{*}$ \\
\hline Other public & 1.83 & 1.83 & 1.81 \\
\hline Private & 16.11 & 16.21 & 14.86 \\
\hline Medicare & 7.99 & 8.06 & $7.02^{\ddagger}$ \\
\hline \multicolumn{4}{|l|}{ Race/ethnicity } \\
\hline Hispanic & 25.22 & 25.42 & 22.73 \\
\hline Black & 19.66 & 19.43 & 22.44 \\
\hline Other race & 12.33 & 12.35 & 11.98 \\
\hline White & 42.68 & 42.67 & 42.85 \\
\hline Male sex & 42.60 & 42.65 & 41.86 \\
\hline \multicolumn{4}{|l|}{ Age (years) } \\
\hline $0-19$ & 30.77 & 30.60 & $32.90^{\ddagger}$ \\
\hline $20-64$ & 61.42 & 61.51 & 60.28 \\
\hline$\geq 65$ & 7.74 & 7.82 & $6.81^{\ddagger}$ \\
\hline
\end{tabular}

Data are mean percentages unless otherwise indicated. PCMH information was available in 2012 only.

Source: Uniform Data System, 2010-2012.

${ }^{*} P<.05$.

${ }^{+} P<.001$.

${ }^{\ddagger} P<.01$.

FPL, federal poverty level.

17,417 patients served annually by non-Beacon health centers (see Table 2). Beacon health centers also had slightly larger pediatric and Medicaid caseloads, and smaller elderly and Medicare caseloads, compared with non-Beacon health centers.

\section{Adoption of Health IT}

Throughout the study period, health centers in Beacon communities were more likely to have an EHR system installed and in use compared with health centers that were not located in Beacon communities. In 2010, 3 of 4 health centers in
Beacon communities used an EHR compared with fewer than 2 of 3 non-Beacon health centers (75.3\% vs $64.0 \% ; P=.04$; see Table 3 ). Beacon health centers were more likely to have an EHR installed in at least 1 site in 2010 compared with health centers that were not located in Beacon communities. Beacon health centers were not more likely than non-Beacon health centers to have an EHR installed in all their clinic sites and used by all providers at baseline in 2010 or to have an EHR system with basic safety and quality functionalities. 
By 2012, 97.7\% of health centers in Beacon communities used an EHR in at least 1 site compared with $89.4 \%$ of non-Beacon health centers $(P=.01)$. Two-thirds of Beacon health centers had EHRs with basic safety and quality features by 2012 (65.9\% compared with $48.5 \%$ of non-Beacon health centers; $P<.01$ ). Beacon health centers were 1.7 times more likely to adopt EHRs with basic safety and quality features between 2010 and 2012, on the basis of adjusted analyses that hold health center and patient caseload characteristics constant (see Table 4).

\section{Use of Health IT to Enable Structured Data Capture and Management}

Both at baseline and in 2012, health centers in Beacon communities were more likely to use the majority of functionalities in all domains examined in this study. Overall, the most commonly used functionalities were those that enable structured data capture and order and results management (see Table 5). In 2010, about two-thirds of health centers used health IT for patient records (63.9\%). By 2012, close to $90 \%$ of all health centers and $>96 \%$ of Beacon health centers used health IT for structured data capture of data elements in patient records, such as patient history and demographic information; creating and maintaining lists; and recording clinical notes.

Managing orders and results for prescriptions, labs, and radiology is another key health IT functionality. Overall e-prescribing rates increased over the study period, from half of all health centers in 2010 to $86.3 \%$ in 2012. By 2012, $95.3 \%$ of Beacon health centers transmitted prescriptions electronically to pharmacies, and the difference between Beacon and non-Beacon health centers became significant $(P=.01)$. Electronic ordering was used less often for lab and radiology orders, and there was no significant difference in the use of electronic ordering for labs and radiology tests between Beacon and non-Beacon health centers in 2010 or in 2012.

\section{Clinical Decision Support}

Use of clinical decision support (CDS) increased sharply in all health centers over the study period. While only half of all health centers used reminders for guideline-based interventions or tests in 2010 (51.1\%), 4 of 5 health centers used health IT to perform this function in 2012 (80.1\%). Beacon health centers were more likely to use reminders in 
Table 4. Factors Associated With Gaining Basic Electronic Health Record Capability Between 2010 and 2012

\begin{tabular}{|c|c|c|}
\hline Covariate & Adjusted Odds Ratio (95\% CI) & $P$ Value \\
\hline \multicolumn{3}{|l|}{ Beacon } \\
\hline Yes & $1.71(1.31-2.24)^{*}$ & .00 \\
\hline No (reference) & 1 & \\
\hline \multicolumn{3}{|l|}{ Rural } \\
\hline Yes & $0.90(0.74-1.09)$ & .27 \\
\hline No (reference) & 1 & \\
\hline \multicolumn{3}{|l|}{ Region } \\
\hline South (reference) & 1 & \\
\hline Northeast & $1.26(0.99-1.61)$ & .06 \\
\hline Midwest & $1.23(0.98-1.54)$ & .07 \\
\hline West & $0.83(0.66-1.04)$ & .11 \\
\hline Size (patients served annually/1000) & $1.00(0.99-1.00)$ & .07 \\
\hline Poverty (<100\% FPL) & $1.01(1.00-1.01)^{*}$ & .00 \\
\hline \multicolumn{3}{|l|}{ Insurance status and type } \\
\hline Lacking health insurance & $0.99(0.98-1.00)^{*}$ & .00 \\
\hline Covered by Medicaid & $0.99(0.98-1.00)^{\dagger}$ & .01 \\
\hline Other types of insurance (reference) & 1 & \\
\hline \multicolumn{3}{|l|}{ Race/ethnicity } \\
\hline Hispanic & $1.00(1.00-1.00)$ & .91 \\
\hline Black & $1.00(0.99-1.00)$ & .23 \\
\hline Other race & $1.00(0.99-1.00)$ & .25 \\
\hline White, non-Hispanic (reference) & 1 & \\
\hline \multicolumn{3}{|l|}{ Year } \\
\hline 2010 & $0.92(0.77-1.11)$ & .39 \\
\hline 2011 & $0.95(0.80-1.14)$ & .61 \\
\hline 2012 (reference) & 1 & \\
\hline
\end{tabular}

Source: Uniform Data System, 2010-2012.

${ }^{*} P<.001$.

${ }^{\dagger} P<.01$.

CI, confidence interval; FPL, federal poverty level.

both 2010 and $2012(P<.05$ in 2010 and $P<.001$ in 2012), and reminder use among Beacon health centers increased to $95.3 \%$ in 2012 . Use of health IT to prompt a tobacco cessation intervention, when appropriate, doubled over the study period and was in use in 2 of 3 health centers $(67.2 \%)$ by 2012.

\section{Engaging Patients and Families}

In $2010,41.1 \%$ of health centers had the capability to provide patients with an electronic copy of their health information upon request. In 2012, 7 of 10 health centers had this capability $(71.0 \%)$, and the gap between Beacon and non-Beacon health centers had disappeared. After-visit clinical summaries were available to patients in half of health centers in $2010(52.1 \%)$ and $85.1 \%$ of health centers in 2012 . Beacon health centers were more likely to provide after-visit clinical summaries in both years compared with non-Beacon health centers $(P<.01$ for 2010 and $P<.001$ in 2012).

\section{Health Information Exchange for Care Coordination, Performance Measurement, and Public Health}

The capability to exchange electronically key clinical information among providers of care and patient-authorized entities increased more sharply in the Beacon group. At baseline, an average of 1 of 3 health centers used this functionality (32.5\%), and there was no significant difference between Beacon and non-Beacon health centers. By 2012, more than 2 of 3 Beacon health centers used health IT to support care coordination (69.4\%) compared with $54.0 \%$ of non-Beacon health centers $(P=.01)$. 


\begin{tabular}{|c|c|c|c|c|c|c|c|c|}
\hline & \multicolumn{6}{|c|}{ Health Centers Using Each Functionality (\%) } & \multicolumn{2}{|c|}{$\begin{array}{l}\text { Percentage Point } \\
\text { Difference } \\
\text { Between Beacon } \\
\text { and Non-Beacon }\end{array}$} \\
\hline & \multicolumn{3}{|c|}{2010} & \multicolumn{3}{|c|}{2012} & \multirow[b]{2}{*}{2010} & \multirow[b]{2}{*}{2012} \\
\hline & Overall & Non-Beacon & Beacon & Overall & Non-Beacon & Beacon & & \\
\hline \multicolumn{9}{|l|}{ Structured data capture } \\
\hline $\begin{array}{l}\text { Patient history and } \\
\text { demographic } \\
\text { information }\end{array}$ & 63.94 & 63.01 & 75.29 & 89.57 & 88.95 & 97.65 & $12.28^{*}$ & $8.70^{*}$ \\
\hline \multicolumn{9}{|l|}{$\begin{array}{l}\text { Electronic order } \\
\text { transmission }\end{array}$} \\
\hline Prescriptions & 50.40 & 49.61 & 60.00 & 86.31 & 85.62 & 95.29 & 10.39 & $9.67^{*}$ \\
\hline Lab orders & 49.96 & 49.33 & 57.65 & 74.46 & 73.85 & 82.35 & 8.32 & 8.50 \\
\hline Radiology orders & 21.73 & 21.39 & 25.88 & 34.89 & 35.49 & 27.06 & 4.49 & -8.43 \\
\hline \multicolumn{9}{|l|}{ Clinical decision support } \\
\hline $\begin{array}{l}\text { Guideline-based reminders } \\
\text { for interventions or tests }\end{array}$ & 51.11 & 50.19 & 62.35 & 80.05 & 78.89 & 95.29 & $12.16^{*}$ & $16.40^{\dagger}$ \\
\hline $\begin{array}{l}\text { Prompt for and record of } \\
\text { tobacco cessation } \\
\text { intervention }\end{array}$ & 34.91 & 34.10 & 44.71 & 67.20 & 66.49 & 76.47 & $10.61^{\ddagger}$ & 9.98 \\
\hline \multicolumn{9}{|l|}{$\begin{array}{l}\text { Engaging patients and } \\
\text { families }\end{array}$} \\
\hline $\begin{array}{l}\text { Capability to provide } \\
\text { patients with an } \\
\text { electronic copy of their } \\
\text { health information upon } \\
\text { request }\end{array}$ & 41.14 & 40.27 & 51.76 & 70.95 & 70.97 & 70.59 & $11.49^{*}$ & -0.38 \\
\hline $\begin{array}{l}\text { Capacity to give clinical } \\
\text { summaries to patients } \\
\text { after visits }\end{array}$ & 52.09 & 51.16 & 63.53 & 85.06 & 84.28 & 95.29 & $12.37^{*}$ & $11.01^{\ddagger}$ \\
\hline \multicolumn{9}{|l|}{$\begin{array}{l}\text { Care coordination and } \\
\text { performance } \\
\text { measurement }\end{array}$} \\
\hline $\begin{array}{l}\text { Capability to exchange key } \\
\text { clinical information }\end{array}$ & 32.50 & 31.98 & 38.82 & 55.09 & 54.00 & 69.41 & 6.84 & $15.41^{\ddagger}$ \\
\hline $\begin{array}{l}\text { Electronically submit } \\
\text { clinical measures }\end{array}$ & 49.87 & 49.33 & 56.47 & 70.78 & 70.17 & 78.82 & 7.14 & 8.65 \\
\hline \multicolumn{9}{|l|}{ Public health } \\
\hline $\begin{array}{l}\text { Disease notifications sent } \\
\text { electronically }\end{array}$ & 11.58 & 11.46 & 12.94 & 18.61 & 18.69 & 17.65 & 1.48 & -1.04 \\
\hline $\begin{array}{l}\text { Electronic reporting to } \\
\text { immunization registries }\end{array}$ & 21.37 & 21.00 & 25.88 & 36.14 & 35.76 & 41.18 & 4.88 & 5.42 \\
\hline
\end{tabular}

Source: 2010 and 2012 Uniform Data System.

The significance between Beacon and non-Beacon usage rates for each functionality was tested using independent samples differences in means $t$ tests: ${ }^{*} P<.05,{ }^{\dagger} P<.001,{ }^{\ddagger} P<.01$.

Reporting quality measures is another type of information exchange. In 2010, about half of all health centers used health IT to electronically abstract and submit data to report the clinical performance measures to the HRSA (49.9\%). In 2012 this number had risen to $70.8 \%$. There was not a significant difference in either year between Beacon and non-Beacon health centers in terms of electronically reporting clinical measures.
The health IT functionalities related to public health were the least commonly found throughout the study period, and there was no difference between Beacon and non-Beacon health centers in 2010 or in 2012. Overall, 1 of 10 health centers electronically reported notifiable diseases in 2010 $(11.6 \%)$, rising to almost 1 of 5 of all health centers in 2012 (18.6\%). Reporting to immunization registries was done electronically by 1 of 5 health 
centers in $2010(21.4 \%)$ and 1 of 3 health centers in $2012(36.1 \%)$.

\section{Discussion}

The use of EHRs with basic quality and safety features grew faster in Beacon health centers over the study period, as did the use of advanced health IT functionalities, particularly health information exchange for care coordination. It is notable that EHR adoption was widespread and rapidly increasing in all health centers throughout the study period, particularly in terms of functionalities that enable quality improvement, including structured data capture, order and results management, and CDS. However, adoption lagged for functionalities supporting patient engagement, care coordination, performance measure reporting, and public health.

The widespread adoption of EHRs and the use of health IT for structured data capture, e-prescribing and electronic ordering, and CDS provides evidence that the HITECH Act spurred adoption of these functionalities across the health care system, including in the safety net. Consistent with previous research, ${ }^{22}$ the high and rapidly increasing EHR adoption rate observed among health centers indicates that health centers are not falling behind other types of providers; in fact, health centers are at the forefront of adopting and using health IT. For EHR adoption, as well as many of the functionalities examined in this study, adoption was higher among Beacon communities in both 2010 and 2012. For some of the functionalities, health centers in Beacon communities had higher values at baseline, so slower growth for these functionalities occurred in Beacon health centers.

Notably, health centers in Beacon communities made significantly greater strides in the critical area of EHR functionalities supporting care coordination compared with non-Beacon health centers. The rapid increase in health information exchange for care coordination in Beacon health centers highlights the importance of broad community partnerships and activation around using health IT to coordinate care. The capability to exchange electronically key clinical information among providers of care and patient-authorized entities is critical for care coordination, and this exchange usually occurs with community partners. The partnerships that were forged and strengthened by the application process for the Beacon program later supported and fueled health information exchange. These findings highlight the importance of infrastructure investments, including robust partnerships, focused at the community level to fulfill the promise of using interoperable health IT for care coordination. In addition to the sources of technical assistance available to all health centers, health centers and other providers in Beacon communities received targeted technical assistance, and communities of practice were created to support the exchange of best practices. Beacon communities were required to submit performance measures and received technical assistance on extracting data and reporting. ${ }^{32}$ As part of the Beacon program, health centers and other providers in Beacon communities received support with using Medicare claims-based quarterly feedback reports for quality improvement. These supplemental sources of support and technical assistance that were available only to health centers in Beacon communities might explain the faster growth of some of the functionalities and the adoption of EHRs with basic safety and quality features in Beacon communities.

Less robust adoption occurred for health IT functionalities that support patient engagement and public health, despite the financial incentives in place through the EHR incentive programs, which require the use of certified EHR products that include these functionalities. Notably, many of the functionalities with lagging adoption rates support activities that occur outside patient visits. Since the predominantly fee-for-service reimbursement system supports only activities that occur during patient visits, the lack of financial support for these functionalities might explain the lagging adoption rates. In addition to reimbursement for these activities, these findings highlight the need for technical assistance with using the sophisticated health IT functionalities that must be more widely used to fully realize the potential of health IT to improve quality and population health. For Beacon and non-Beacon health centers, outreach efforts should connect health centers with available sources of technical assistance, such as health center controlled networks, which are groups of health centers that band together to share knowledge and resources to address infrastructure, quality improvement, and patient care needs. Other entities such as regional extension centers and practicebased research networks also support the use of health IT to improve quality and provide other 
services such as medical home transformation support. ${ }^{3-35}$ In addition, HRSA funds technical assistance through national and state associations that act as conveners and conduits of information and best practices for health IT adoption and use of advanced functionalities.

Limitations of this study include the possibility of unobserved systematic differences between Beacon communities and the rest of the country, and thus between health centers in Beacon communities and those located elsewhere (all health centers located in a Beacon community participated in the program). Since Beacon communities were selected based on robust preexisting EHR adoption and health information exchange, their experiences may not be easily generalizable nationwide. However, it is still important to understand trends among early adopters of health IT and, given their more rapid improvement in key areas, to examine what factors enabled them to make such progress. Multivariate regression modeling was used in this study to control for differences between Beacon health centers and health centers not located in Beacon communities. Another limitation is the fact that the UDS is reported at the organization level, not the care delivery site level. The data were self-reported, but validation is performed. Health centers are located across the nation, and this analysis does not control for geographic proximity between Beacon and nonBeacon health centers. Finally, it is difficult to evaluate large-scale efforts to spur the adoption of health IT, such as the Beacon program, because of the importance of context, the complexity and heterogeneity of the intervention, and the unpredictable path of the dissemination of innovations. ${ }^{32}$

Topics for future research include more closely examining the specific activities and goals of each Beacon community to see how health center participation was shaped by variation in the type of interventions. Future research should examine the potential impact of the Beacon program on health IT adoption and use beyond 2012, since the benefits of health IT do not accrue immediately and the implementation period can be challenging. Since the functionalities with the lowest adoption ratesincluding patient engagement, care coordination, performance measurement, and public healthsupport non-encounter-based activities, future research should focus on factors that may facilitate or hinder adoption and use of these functions. Qualitative exploration of barriers and facilitators that health centers faced in participating with Beacon communities and the lessons learned would be informative. Future studies should examine how best to support health centers and other providers with reengineering clinical workflow and using health IT and health information exchange ${ }^{36}$ to improve quality, ${ }^{37,38}$ patient experience, ${ }^{39}$ and care coordination. $^{40,41}$

\section{Conclusion}

Health IT is critical to national, state, and community-based efforts to improve quality, cost-effectiveness, and population health for all Americans. These findings highlight the importance of community-based efforts to transform health care that foster widespread adoption of health IT capable of securely sharing data with other providers, coupled with technical assistance and layered investments. The additive effects of 3 factors might have contributed to accelerated adoption of EHRs in Beacon health centers: technical assistance, community-wide partnerships and activation, and the layering of different financial incentives. The HITECH Act spurred adoption of EHRs with basic safety and quality features, but further work is needed to effectively use health IT to engage patients, coordinate care, measure quality, and engage with public health entities.

The authors thank Ed Lomotan and Anna Poker, from the Health Resources and Services Administration, and Jennifer King, Alex Baker, and Rhonda Poirier, from the Office of the National Coordinator for Health Information Technology, for commenting on the preliminary findings. The authors also acknowledge Michael Furukawa of the Agency for Healthcare Research and Quality for coding some of the variables used in this study.

\section{References}

1. Walker J, McKethan A. Achieving accountable care"It's not about the bike." N Engl J Med 2012;366:e4.

2. Buntin MB, Jain SH, Blumenthal D. Health information technology: laying the infrastructure for national health reform. Health Aff (Millwood) 2010;29: 1214-9.

3. Fineberg H. A successful and sustainable health system-how to get there from here. $\mathrm{N}$ Engl $\mathrm{J}$ Med 2012;366:1020-7.

4. Health Information Technology for Economic and Clinical Health (HITECH) Act. PL 111-5, 123 Stat 226, 42 USC. February 7, 2009.

5. Blumenthal D. Launching HITECH. New Eng J Med 2010;362:382-5. 
6. Marcotte L, Seidman J, Trudel K, et al. Achieving meaningful use of health information technology. Arch Intern Med 2012;172:731-6.

7. Blumenthal D. Wiring the health system-origins and provisions of a new federal program. N Engl J Med 2011;365:2323-9.

8. Blumenthal D. Implementation of the federal health information technology initiative. $\mathrm{N}$ Engl J Med 2011;265:2426-31.

9. Supporting health information technology adoption in federally qualified health centers. Washington, DC: Office of the National Coordinator for Health Information Technology; 2013.

10. Lynch K, Kendall M, Shanks K, et al. The Health IT Regional Extension Center Program: evolution and lessons for health care transformation. Health Serv Res 2014;49(1 Pt 2):421-37.

11. Gold M, McLaughlin C, Devers K, Berenson R, Bovjberg R. Obtaining providers' 'buy-in' and establishing effective means of information exchange will be critical to HITECH's success. Health Aff (Millwood) 2012;31:514-26.

12. Hsiao CJ, Jha AK, King J, Patel V, Furukawa MF, Mostashari F. Office-based physicians are responding to incentives and assistance by adopting and using electronic health records. Health Aff (Millwood) 2013;32:1470-7.

13. DesRoches CM, Charles D, Furukawa MF, et al. Adoption of electronic health records grows rapidly, but fewer than half of US hospitals had at least a basic system in 2012. Health Aff (Millwood) 2013; 32:1478-85.

14. Maxson ER, Jain SH, McKethan AN, et al. Beacon communities aim to use health information technology to transform the delivery of care. Health Aff (Millwood) 2010;29:1671-7.

15. Fairbrother G, Trudnak T, Christopher R, Mansour M, Mandel K. Cincinnati beacon community program highlights challenges and opportunities on the path to care transformation. Health Aff (Millwood) 2014;33:871-7.

16. McKethan A, Brammer C, Fatemi P, et al. An early status report on the Beacon Communities' plans for transformation via health information technology. Health Aff (Millwood) 2011;30:782-8.

17. Miller RH, D'Amato K, Oliva N, West CE, Adelson JW. California's digital divide: clinical information systems for the haves and have-nots. Health Aff (Millwood) 2009;28:505-16.

18. Bahensky JA, Jaana M, Ward MM. Health care information technology in rural america: electronic medical record adoption status in meeting the national agenda. J Rural Health 2008;24:101-5.

19. Hawkins D, Groves D. The future role of community health centers in a changing health care landscape. J Ambul Care Manage 2011;34:90-9.

20. Shin P, Jones E, Jacobs F, Tuckson R. Building a national data repository to measure and improve health center quality. J Ambul Care Manage 2010; 33:307-13.

21. Chin M, Kirchoff A, Schlotthauer A, et al. Sustaining quality improvement in community health centers: perceptions of leaders and staff. J Ambul Care Manage 2008;31:319-29.

22. Braun, B. Owens L, Bartman B, Berkeley L, Wineman N, Daly C. Quality-related activities in federally supported health centers: do they differ by organizational characteristics? J Ambul Care Manage 2008;31:303-18.

23. Cebul RD, Love TE, Jain AK, Hebert CJ. Electronic health records and quality of diabetes care. N Engl J Med 2011;365:825-33.

24. Fiscella K, Geiger HJ. Health information technology and quality improvement for community health centers. Health Aff (Millwood) 2006;25:405-12.

25. Frimpong JA, Jackson BE, Stewart LM, Singh KP, Rivers PA, Bae S. Health information technology capacity at federally qualified health centers: a mechanism for improving quality of care. BMC Health Serv Res 2013;13:35.

26. DeVoe J, Gold R, Cottrell E, et al. The ADVANCE network: accelerating data value across a national community health center network. J Am Med Inform Assoc 2014;21:591-5.

27. Jones E, Furukawa M. Adoption and use of electronic health records among federally qualified health centers grew substantially during 2010-2. Health Aff (Millwood) 2014;33:1254-61.

28. Wittie M, Ngo-Metzger Q, Lebrun-Harris L, Shi L, Nair S. Enabling quality: electronic health record adoption and meaningful use readiness in federally funded health centers. J Healthc Qual 2015 Apr 22 [Epub ahead of print].

29. DesRoches CM, Campbell EG, Rao SR, et al. Electronic health records in ambulatory care-a national survey of physicians. N Engl J Med 2008;359:50-60.

30. Hing E, Hsiao CJ. Electronic medical record use by office-based physicians and their practices: United States, 2007. Natl Health Stat Rep 2010;(23):1-11.

31. Shields AE, Shin P, Leu MG, et al. Adoption of health information technology in community health centers: results of a national survey. Health Aff (Millwood) 2007;26:1373-83.

32. Jones E, Swain M, Patel V, Furukawa M. Supporting HITECH implementation and assessing lessons for the future: the role of program evaluation. Healthc (Amst) 2014;2:4-8.

33. DeVoe J, Gold R, Spofford M, et al. Developing a network of community health centers with a common electronic health record: description of the Safety Net West Practice-Based Research Network (SNW-PBRN). J Am Board Fam Med 2011;24:597604.

34. Petersen K, Fontaine P, Speedie S. The electronic Primary Care Research Network (ePCRN): a new 
era in practice-based research. J Am Board Fam Med 2006;19:93-7.

35. Nagykaldi Z, Mold J. The role of health information technology in the translation of research into practice: an Oklahoma Physicians Resource/Research Network (OKPRN) study. J Am Board Fam Med 2007;20:188-95.

36. Fontaine P, Ross S, Zink T, Schilling L. Systematic review of health information exchange in primary care practices. J Am Board Fam Med 2010; 23:655-70.

37. Orzano J, Strickland P, Tallia A, et al. Improving diabetes outcomes for high-risk diabetics using information systems. J Am Board Fam Med 2007;20: $245-51$.
38. Crosson J, Schueth A, Isaacson N, Bell D. Early adopters of electronic prescribing struggle to make meaningful use of formulary checks and medication history documentation. J Am Board Fam Med 2012; 25:24-32.

39. Irani J, Middleton J, Marfatia R, Omana E, D'Amico $\mathrm{F}$. The use of electronic health records in the exam room and patient satisfaction: a systematic review. J Am Board Fam Med 2009;22:553-62.

40. O'Malley A. Tapping the unmet potential of health information technology. N Engl J Med 2011;364: 1090-1.

41. Stille C, Primack W. Interspecialty communication: old problem, new hope? Arch Intern Med 2011;171: 1300 . 